\title{
SISTEM INFORMASI ADMINISTRASI PEMBAYARAN BERBASIS APLIKASI WEB STUDI KASUS PADA SMK AL-WAHDAH CITERAS SERANG-BANTEN
}

\author{
Khasan Asrori ${ }^{1}$, Ely Nuryani ${ }^{2}$ \\ Fakultas Ilmu Komputer Universitas Banten Jaya \\ Jl. Ciwaru Raya II No. 73 Warung Pojok Kota Serang Banten \\ E-mail: khasanasrori@gmail.com ${ }^{1}$, elynuryani@ unbaja.ac.id ${ }^{2}$
}

\begin{abstract}
The research outlined in this title aims to design a system that can facilitate the payment administration process. The research method used is descriptive research method. Descriptive method is a method of researching an object that aims to make a description, picture or painting in a systematic, factual and accurate manner about the facts, properties and relationships between the phenomenon under investigation. And the Waterfall system design method which in this method has the stages of Planning, Requirement Analysis, Design, Implementation, Testing and Documentation. Finally, after analysing and discussing the problem, it was concluded that a more flexible payment administration system was needed for SMK Al-Wahdah. Due to the existing system at Al-Wahdah Vocational School, there is a lot of damage and it is not flexible
\end{abstract}

Keywords : information system, payment administration, Waterfall

\section{PENDAHULUAN}

Era globalisasi sekarang ini perkembangan ilmu pengetahuan dan teknologi sangatlah pesat. Seiring dengan meningkatnya kebutuhan manusia selalu mencari cara termudah untuk mendapatkan informasi yang dibutuhkannya, karena masalah waktu bagi masyarakat maju adalah suatu yang sangat berharga.

Al-Wahdah adalah suatu instansi bergerak dibidang pendidikan umum dan agama yang berbasis pondok pesantren salafi, namun terdapat beberapa sekolahan mulai tingkat Madrasah Ibtidaiyah (MI), Sekolah Menengah Pertama (SMP) hingga Sekolah Menengah Kejuruan Terpadu (SMK T), di bawah pimpinan serta pendiri K.H Dr. A. Bajari Syam, M.Pd.

Peranan teknologi informasi di bidang pendidikan sangat penting karena sistem adalah sesuatu yang kompleks dan mencakup dimensi manusia sebagai pengguna dan mencakup berbagai disiplin ilmu (Yulia, Rahmat Fauzi, 2018). Kita tahu bahwa pelayanan pendidikan memerlukan pelayanan yang cepat, tepat dan 
akurat. Di dalam hal ini teknologi informasi yang di terapkan di dalam dunia pendidikan sangat berperan penting. Tidak hanya akan dirasakan manfaatnya oleh para penggunanya, tetapi juga oleh organisasi, perusahaan dan instansi yang terkait di bidang pendidikan tersebut.

Sistem adalah rangkaian dari dua atau lebih komponen-komponen yang saling berhubungan, yang berinteraksi untuk mencapai suatu tujuan.Sebagian besar sistem terdiridari subsistem yang lebih kecil yang mendukung sistem yang lebih besar. (Romney dan Steinbart, 2015) Maka dari itu terbuatnya aplikasi ini untuk memudahkan melakukan pembayaran administrasi pada SMK Al-Wahdah.

Perangkat ini secara tidak langsung dapat memudahkan untuk melakukan pekerjaan dengan cepat. Sehingga memerlukan suatu teknologi software yang dapat mengatur semua secara menyeluruh. Pada dasarnya di SMK Al-Wahdah belum menggunakan sistem terkomputerisasi, oleh karena itu sering sekali terjadi berbagai macam kendala di saat proses pembayaran, sehingga membutuhkan waktu yang sangat banyak. Dengan adanya sistem informasi ini diharapkan dapat lebih efisien serta dapat menyimpan data dengan terjamin sehingga mempermudah segala aktifitas pembayaran administrasi.

\section{METODE PENELITIAN}

Penelitian ini dilakukan di SMK Al-Wahdah dan metode pengumpulan data yang digunakan adalah :

a. Observasi : pengumpulan data yang tidak hanya mengukur sikap dari responden namun juga dapat digunakan untuk merekam berbagai fenomena yang terjadi.

b. Interview : pengumpulan data yang dilakukan melalui tatap muka dan tanya jawab langsung.

c. Research : pengumpulan data dengan mengambil data dari berbagai sumber.

\section{METODE ANALISA DAN PERANCANGAN}

Analis sistem didefinisikan sebagai bagaimana memahami dan menspesifikasi dengan detail apa yang harus dilakukan oleh sistem. Sementara 
sistem desain diartikan sebagai menjalankan dengan detail bagaimana bagianbagian dari sistem informasi diimplementasikan.

Sistem adalah kumpulan orang yang saling bekerja sama dengan ketentuanketentuan aturan yang sistematis dan terstruktur untuk membentuk satu kesatuan yang melaksanakan suatu fungsi untuk mencapai tujuan (Elisabet Yunaeti Anggraeni, 2017)

Dengan demikian, analisis dan desain sistem informasi bisa didefinisikan sebagai proses organisasional komplek dimana sistem informasi berbasis komputer diimplementasikan.

Metode pengembangan yang digunakan oleh penulis dalam penelitian menggunakan metode System Development Life Cycle (SDLC) yang merupakan metodologi umum dalam pengembangan sistem yang menandai kemajuan sistem usaha analisis dan desain.

Daur hidup pengembangan sistem SDLC berfungsi untuk menggambarkan tahapan-tahapan utama dan langkah-langkah dari setiap tahapan.(Melia Dianingrum. "Rancang Bangun Sistem Informasi Pembayaran Sumbangan Penunjang Pendidikan di SMP Muhamadiyah Jeruklegi-Cilacap". Jurnal Telematika, Vol. 5, pp. 107, Febuari 2015) 


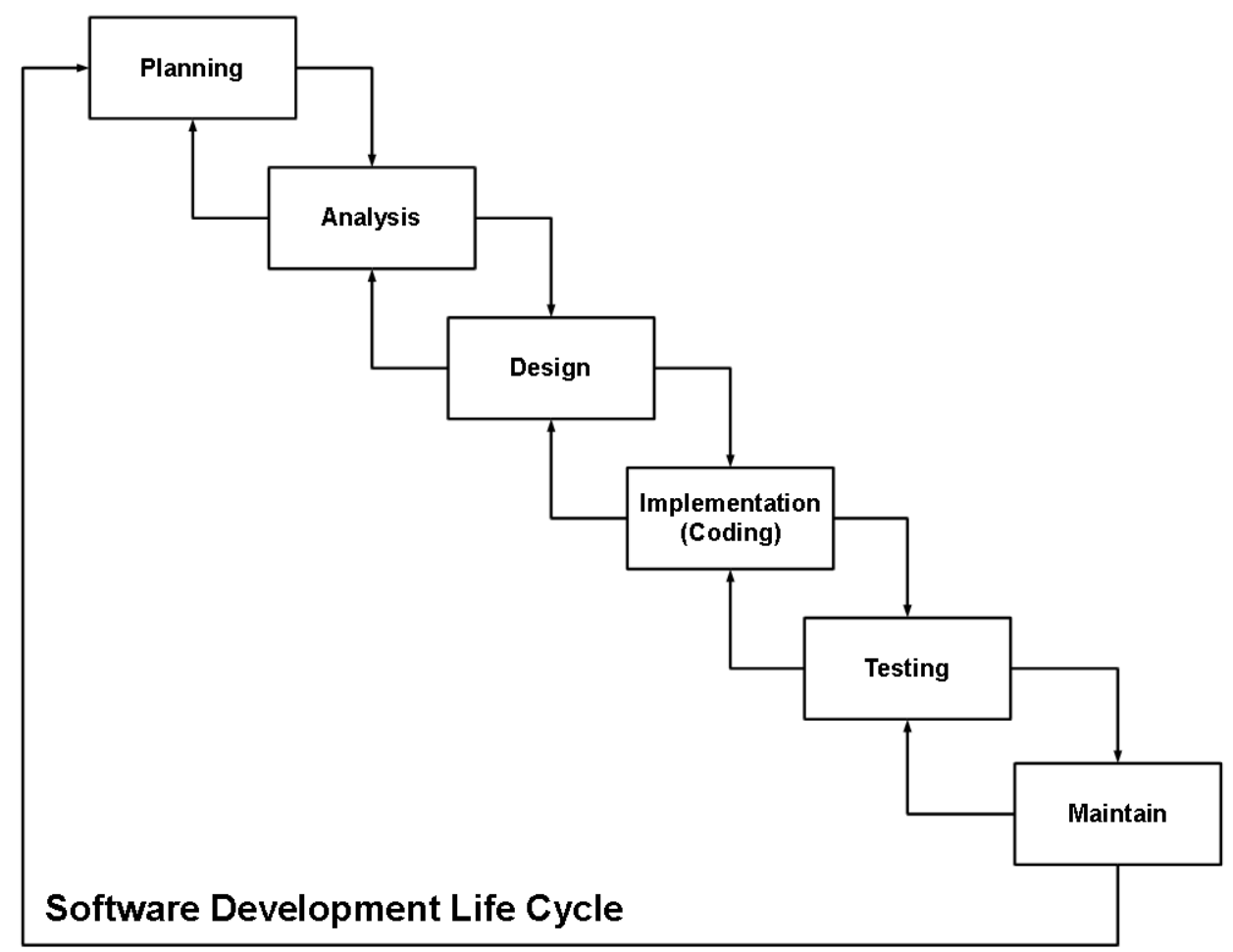

Gambar 1. Alur SDLC

\section{HASIL DAN PEMBAHASAN}

Dalam perancangan sistem informasi pembayaran administrasi spp pada SMK Al-Wahdah, digambarkan menggunakan FOD (Flow Of Document) hampir setiap perancangan sistem memanfaatkan FOD sebagai alat perancangan sistem.

Flow Of Document adalah alat pembuatan model yang memungkinkan profesional sistem untuk menggambarkan sistem sebagai suatu jaringan proses fungsional yang dihubungkan satu dengan yang lainnya dengan alur data baik secara manual maupun secara komputerisasi. 


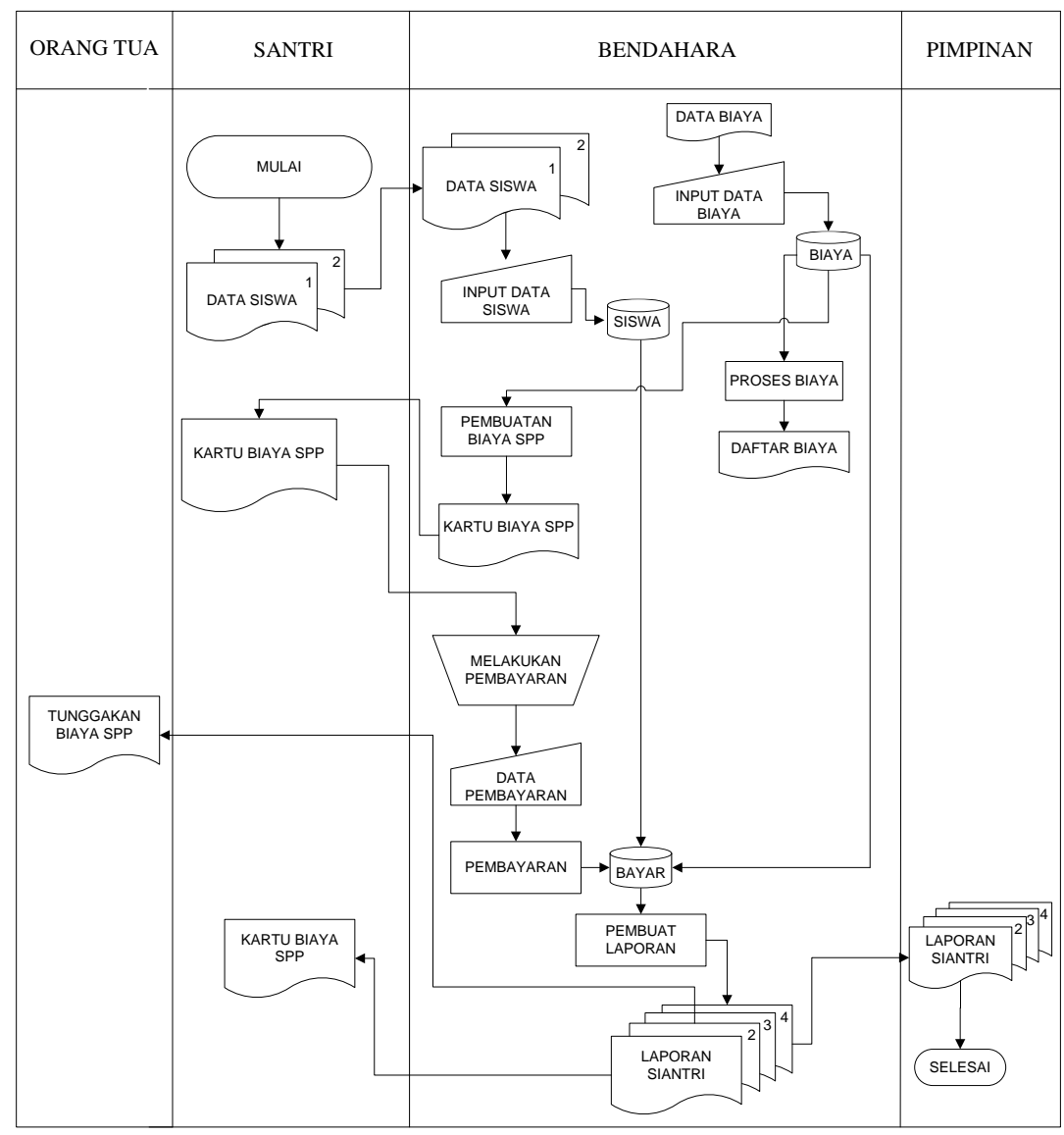

Gambar 2. FOD Sistem Usulan

Flow Of Document (FOD) yang diusulkan dimulai pada bagian santri yang pada bagian ini memberikan data santri kepada bagian bendahara sebanyak 2 (dua) rangkap, rangkap 2 diarsipkan pada bagian bendahara dan rangkap 1 (satu) diproses secara komputerisasi untuk dibuat kartu biaya SPP yang kemudian di serahkan kepada bagian santri.

Pada bagian santri kartu biaya SPP tersebut kemudian dibawa lagi ke bagian bendahara untuk melakukan pembayaran lalu terbitlah dokumen bukti pembayaran iuran sebanyak 2 rangkap yang kemudian diporses secara komputerisasi untuk dibuat dokumen kartu biaya SPP yang sudah ditandatangani sebanyak 2 rangkap. Rangkap 1 diserahkan kepada bagian santri sedangkan rangkap 2 diproses untuk dibuatkan laporan sebanyak 4 (empat) rangkap yaitu laporan daftar siswa, laporan daftar pembayaran biaya SPP, laporan santri yang sudah bayar dan laporan santri yang belum bayar kemudian diserahkan pada bagian pimpinan, data laporan santri 
yang belum melakukan pembayaran atau tunggakan SPP akan diserahkan kepada bagian orangtua. Proses selesai pada bagian pimpinan.

\section{KAMUS DATA}

Tabel 1. Administrasi Kelas

\begin{tabular}{|l|l|l|l|l|}
\hline Column & Type & Null & Default & Comments \\
\hline id_adm_kelas & $\operatorname{int}(11)$ & No & & \\
\hline $\begin{array}{l}\text { id_kelas } \\
\text { (Primary) }\end{array}$ & $\operatorname{int}(11)$ & No & & \\
\hline $\begin{array}{l}\text { id_jenis_biaya } \\
\text { (Primary) }\end{array}$ & $\operatorname{int(11)}$ & No & & \\
\hline tahun_ajaran & varchar(30) & Yes & NULL & \\
\hline wajib & enum('Y', 'N') & Yes & NULL & \\
\hline
\end{tabular}

Tabel 2. Akun Pengguna

\begin{tabular}{|l|l|l|l|l|}
\hline Column & Type & Null & Default & Comments \\
\hline nip (Primary) & varchar(50) & No & & \\
\hline kata_sandi & varchar(255) & Yes & NULL & \\
\hline full_name & varchar(50) & Yes & NULL & \\
\hline email & varchar(200) & Yes & NULL & \\
\hline level & varchar(20) & Yes & NULL & \\
\hline
\end{tabular}

Tabel 3. Bayar Peraktek Rinci

\begin{tabular}{|l|l|l|l|l|}
\hline Column & Type & Null & Default & Comments \\
\hline $\begin{array}{l}\text { no_invoice } \\
\text { (Primary) }\end{array}$ & varchar(255) & No & & \\
\hline $\begin{array}{l}\text { id_bulan } \\
\text { (Primary) }\end{array}$ & int(11) & No & & \\
\hline
\end{tabular}

Tabel 4. Bayar Peraktek Detail

\begin{tabular}{|l|l|l|l|l|}
\hline Column & Type & Null & Default & Comments \\
\hline
\end{tabular}




\begin{tabular}{|l|l|l|l|l|}
\hline $\begin{array}{l}\text { no_invoice } \\
\text { (Primary) }\end{array}$ & varchar(255) & No & & \\
\hline nis & varchar(255) & Yes & NULL & \\
\hline tgl_bayar & date & Yes & NULL & \\
\hline bayar & float & Yes & NULL & \\
\hline sisa & float & Yes & NULL & \\
\hline kembali & float & Yes & NULL & \\
\hline ket_bayar & varchar(255) & Yes & NULL & \\
\hline nip & varchar(255) & Yes & NULL & \\
\hline
\end{tabular}

\section{HASIL IMPLEMENTASI SISTEM}

\section{A. Halaman Login}

Form pertama yang muncul ketika mengakses adalah login, berfungsi untuk memberikan hak akses kepada user untuk mengolah sistem yang telah disediakan. Terdapat 2 level yaitu, operator bertugas untuk mengoprasikan pembayaran administrasi dan administrator bertugas untuk menginput data-data pendukung.

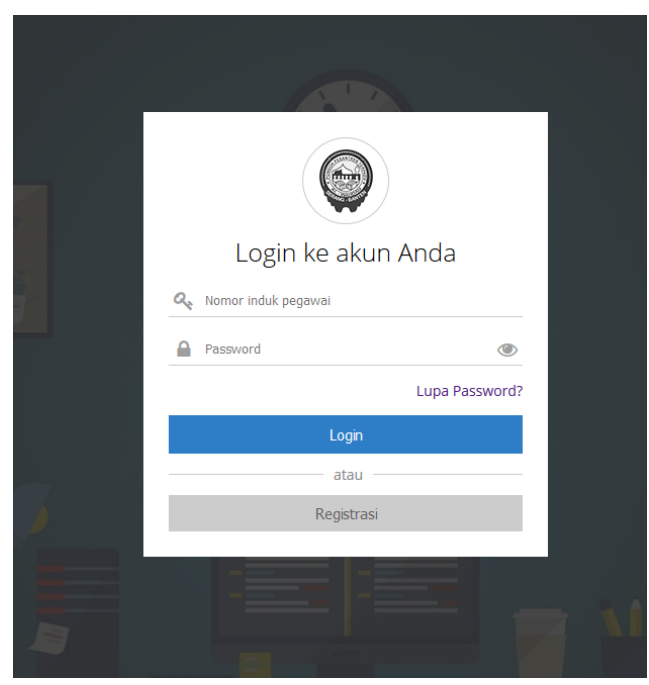

Gambar 3. Halaman Login

\section{B. Halaman Utama}

Menampilkan rancangan halaman utama dari aplikasi setelah login berhasil, terdapat 2 tampilan yaitu halaman operator dan halaman administrator 


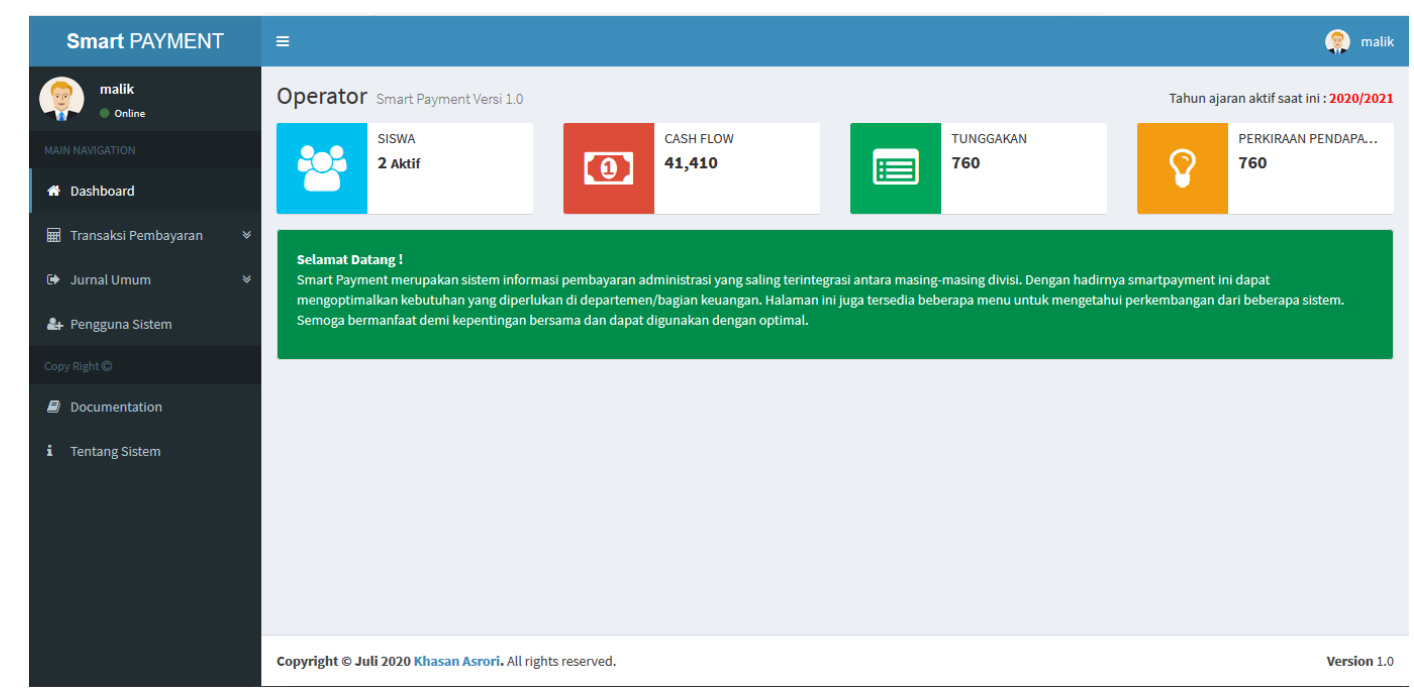

Gambar 4. Halaman Menu Utama operator

Halaman utama pada operator terdiri dari beberapa menu :

1. Transaksi pembayaran peraktek

2. Transakasi pembayaran administrasi

3. Transaksi pengeluaran

4. Transaksi pemasukan

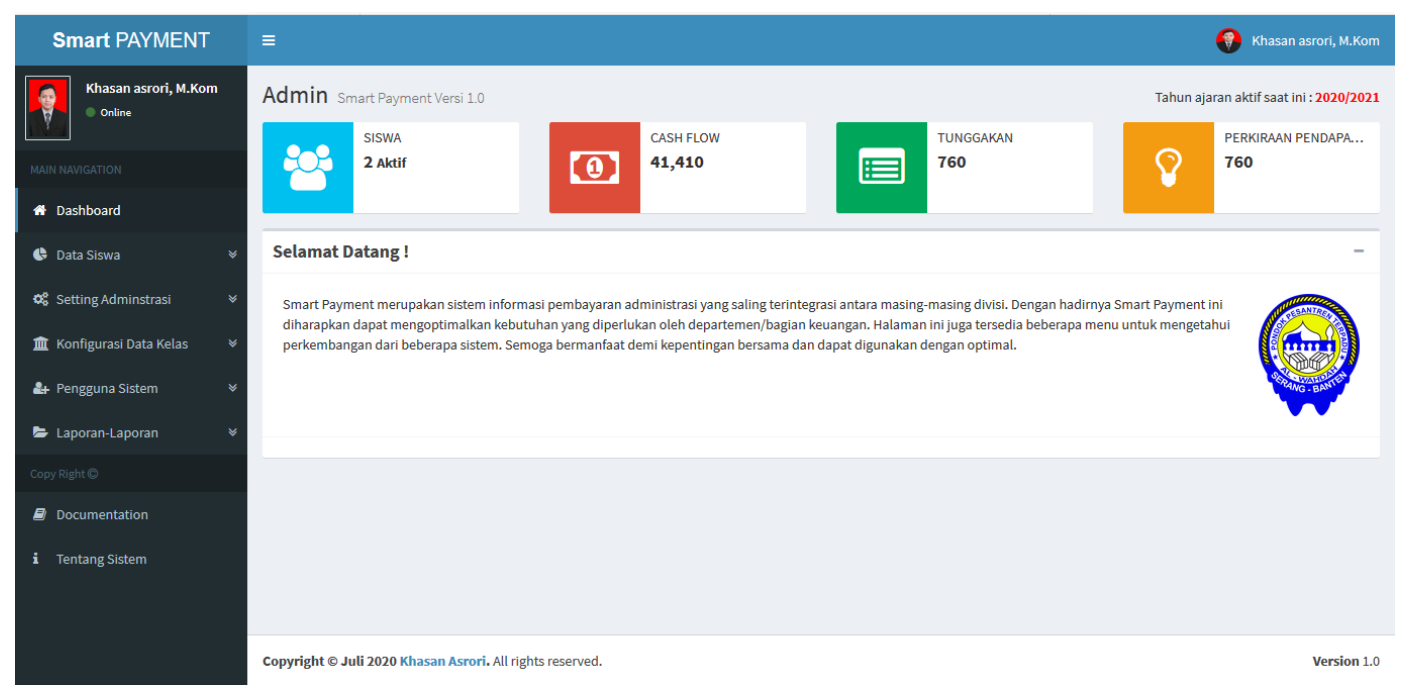

Gambar 5. Halaman Utama Administrator 


\section{Proses Pembayaran}

Pada form ini menjelaskan proses pembayaran terhadapt siswa yang akan melakukan pembayaran peraktek, pembayaran peraktek ini dilakukan setiap bulan sekali.
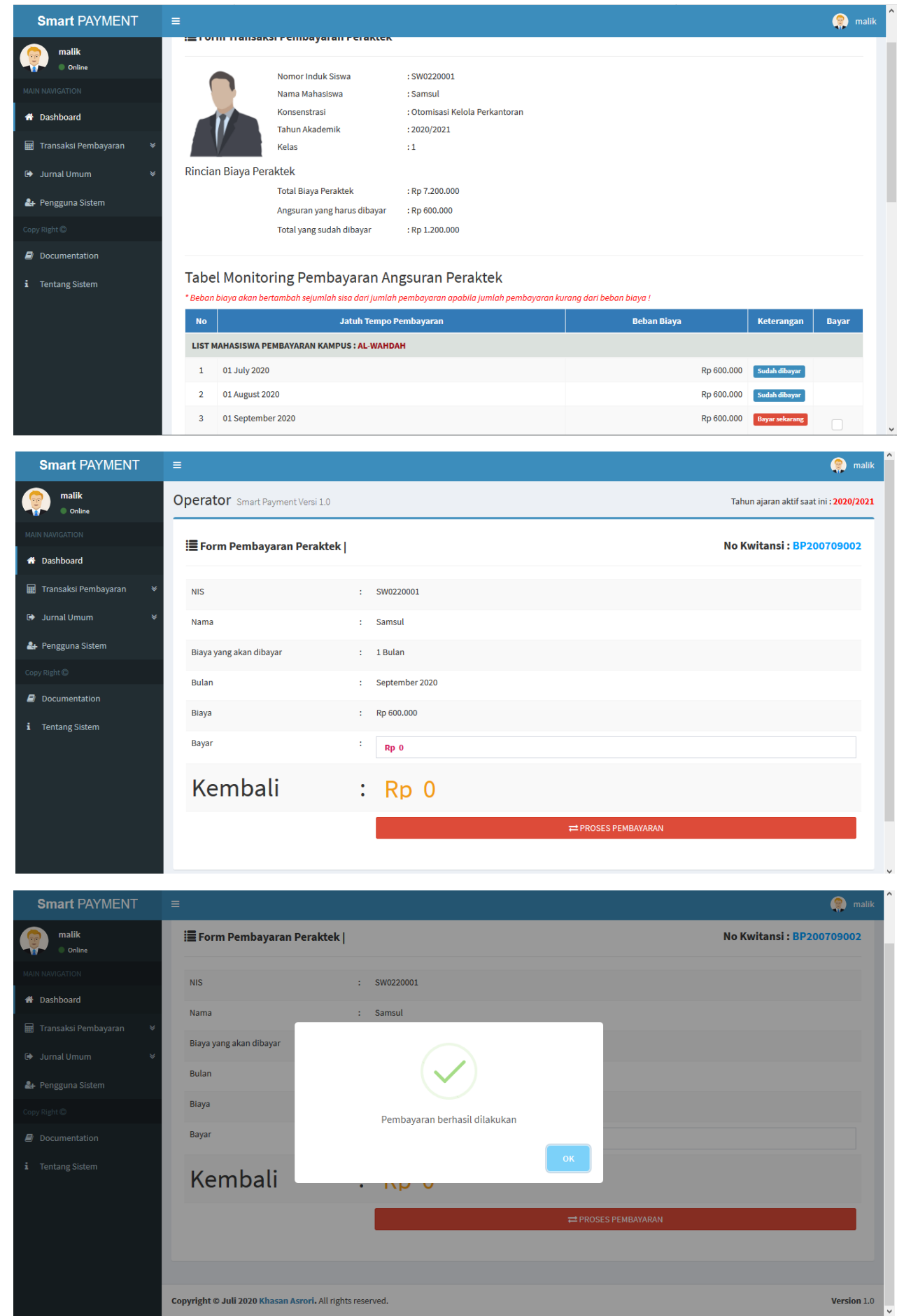

Gambar 6. Halaman proses pembayaran 


\section{Laporan - laporan}

Form laporan ini berfungsi untuk mencetak laporan mulai dari pembayaran praktek, pembayaran administarasi lain, tunggakan-tunggakan dan laporan lain-lainnya.
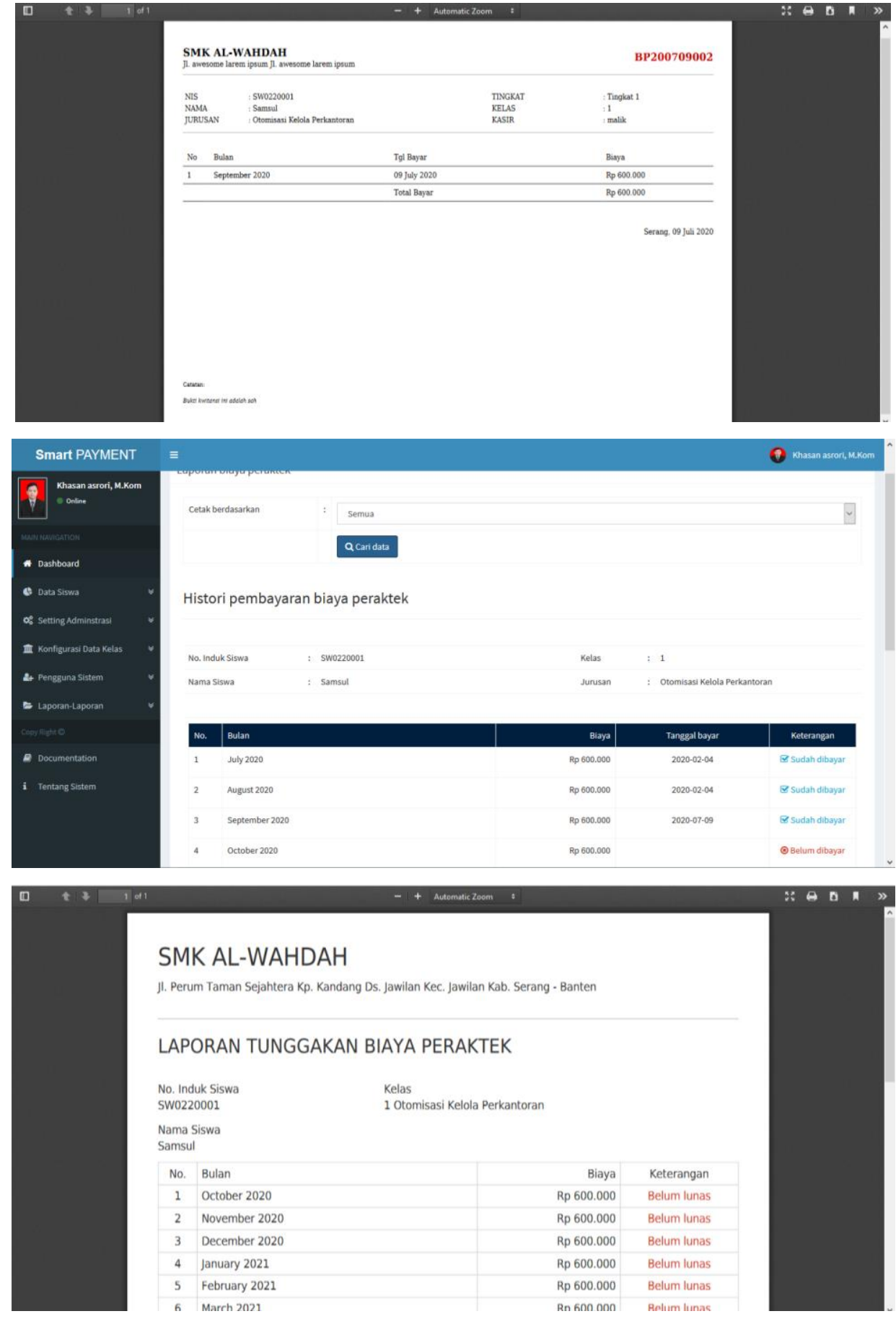

Gambar 7. Laporan-laporan 


\section{KESIMPULAN}

Dari serangkaian penelitian yang dilakukan dengan cara melakukan beberapa pengujian dan percobaan, maka dapat ditarik kesimpulan antara lain :

1. Sistem Informasi Administrasi Pembayaran masih menggunakan pencatatan pada kartu pembayaran siswa

2. Dengan dirancangkan sistem administrasi secara terkomputerisasi diharapkan dapat membantu kegiatan pembayaran administrasi.

\section{SARAN}

Dari kesimpulan di atas yang dapat penulis berikan saran yang ditujukan kepada pihak yayasan, sebagai bahan pertimbangan adalah :

a. Menyiapkan media penyimpanan hosting yang lebih besar

b. Menambahkan fiture SMS Gateway agar siswa dan wali siswa dapat mengetahui pembayaran.

c. Menambahkan fasilitas login untuk siswa agar mengetahui histori pembayaran.

\section{REFRENSI}

Elisabet Yunaeti Anggraeni dan Rita Irviani, (2017) Pengantar Sistem Informasi Edisi I, Yogyakarta; Andi.

Melia Dianingrum (2015) Rancang Bangun Sistem Informasi Pembayaran Sumbangan Penunjang Pendidikan di SMP Muhamadiyah Jeruklegi-Cilacap”. Jurnal Telematika, Vol. 5, pp. 107, Febuari 2015.

Romney, Marshall B. dan Steinbart, (2015) Sistem Informasi Akuntansi Edisi 13, alihbahasa: Kikin Sakinah Nur Safira dan Novita Puspasari, Salemba Empat, Jakarta.

Yulia dan Rahmat Fauzi, (2018) Sistem Informasi Manajemen Batam: UPB, 2018, 13. 